\title{
Accidental release of tritiated water - toward a better radiological assessment
}

\author{
D. Galeriu ${ }^{1}$, A. Melintescu ${ }^{1}$, D. Slavnicu ${ }^{1}$, D. Gheorghiu ${ }^{1}$ and V. Simionov ${ }^{2}$ \\ 1 "Horia Hulubei" National Institute for Physics and Nuclear Engineering, \\ Life and Environmental Physics Department, 407 Atomistilor St., POB MG-6, \\ Bucharest-Magurele, 077125, Romania \\ ${ }^{2}$ CNE-CERNAVODA, 1 Medgidiei st, CP 42, 905200 Cernavoda, Romania \\ e-mail: galdan@ifin.nipne.ro; dangaler@yahoo.com
}

\begin{abstract}
The need of less conservative but reliable risk assessment for accidental tritium release was recognized in the frame of present debate on nuclear energy future. While the fusion reactor is only in research phase and risk assessment are not extremely stringent, Romania faces a debate on near future of nuclear energy with heavy water reactors, known to have a large load and release of tritium. Both tritium and ${ }^{14} \mathrm{C}$ are key radionuclide for CANDU and are also directly involved in the life cycle of plants and animals. An interdisciplinary approach is proposed in order to better handle the environmental transfer of tritium under accidental conditions and preparatory steps are presented.
\end{abstract}

\section{INTRODUCTION}

For design and licensing, as well as for accident preparedness and management at large tritium producer facilities, robust radiological assessment code for accidental release are needed, considering the stronger safety requirements in the present debate for nuclear energy. From our present understanding, the uncertainty in the assessment of accidental tritiated water (HTO) release is still not satisfactory. Recent international exercises [1] show that causes of large uncertainties resides both in the simplicity of atmospheric transport-dispersion and in the understanding-modelling on the transfer of tritium from air to soil-plant-animal. Animals include humans - as target for risk assessment under classical views. In radiation protection, human tritium dosimetry is under debate [2] and overall uncertainty includes human dosimetry, too. For a better robustness in modelling food chain transfer, it needs an enhanced knowledge, recently summarized [3] and the role of site specific assessment was pointed [4]. Before implementing or upgrading specific codes in any DSS (Decision Support Systems developed to support decision makers in a case of a nuclear accident) more steps are needed in order to decrease the assessment uncertainties. This is the main topic of this paper, oriented to conditions in Romania, at Cernavoda, where Nuclear Power Plants are established and will be expanded. They are based on CANDU reactors, with enhanced tritium emission and risk.

\section{THE EXCANGE VELOCITY APPROACH FOR THE TRANSFER FROM AIR TO PLANT AND SOIL}

It is not recommended to use the deposition velocity concept to study air-surface exchange of species as $\mathrm{H}_{2} \mathrm{O}$ and $\mathrm{CO}_{2}$, because they are emitted from and deposit to plant canopies. The rates at which these gases are transferred between the biosphere and the atmosphere depend upon a complex and non-linear interplay among physiological, ecological, biochemical, chemical, and edaphic factors, and meteorological conditions [5]. The dynamic response of ecosystem $\mathrm{CO}_{2}$, water vapour and trace gas exchange to any environmental perturbation is the summation of individual responses of component compartments. Ecosystem $\mathrm{CO}_{2}$ exchange, for example, is comprised of carbon fluxes associated with 
four compartments, leaves, boles, roots and soil organic matter. Canopy evaporation consists of water vapour that is lost through plant transpiration and soil evaporation. The exchange velocity is a useful simplification and depicts the transfer as inverse of a sum of resistances: atmospheric, boundary layer and surface (canopy for exchange with crops) [6]. Canopy resistance integrates leaf stomata resistance on canopy height and it is expected a difference between $\mathrm{C} 3$ and $\mathrm{C} 4$ species because leaves of $\mathrm{C} 3$ species exert a lower stomata resistance than do C4 leaves. Stomata resistance is a function of light, which varies appreciably with depth into the canopy and on sunlit and shaded leaves. We need a dual source model and must incorporate the coupling between vegetation and soil beneath [6]. This needs a better description of soil resistance under the canopy and first attempt were previously reported [6]. Among the many approaches for modelling canopy resistance [5], in this paper, it is used the direct link with canopy photosynthesis (A-g model) and the operational model of photosynthesis from Wageningen school [6], avoiding to solve highly non-linear and coupled equations. An advantage of an A-g model is that the calculations are based on simple plant characteristics, for example, whether the vegetation uses the $\mathrm{C} 3$ or $\mathrm{C} 4$ metabolism, and on atmospheric variables that are measured on a routine basis at a standard meteorological observation site. Recently, it was improved the approximation for the canopy conductance [7] as:

$$
g_{c, w}=g_{\min , w} * L A I+\frac{a_{1} * A_{g, c} * f\left(\theta_{r}\right)}{\left(C_{s}-\Gamma\right) *\left(\Gamma+\frac{D_{s}}{D_{*}}\right)}
$$

with $\mathrm{g}_{\text {min,w }}$ - cuticle conductance for water; LAI - leaf area index; $\mathrm{C}_{\mathrm{s}}$ - the $\mathrm{CO}_{2}$ concentration at the leaf surface, $\Gamma\left(\mathrm{mg} \mathrm{m}^{-3}\right)$ is the $\mathrm{CO}_{2}$ compensation point, $D_{s}(\mathrm{~Pa})$ is the vapour pressure deficit at plant level; $\mathrm{f}\left(\theta_{r}\right)$ is correction for soil water stress and $a_{1}$ and $D^{*}$ are empirical quantities defined, as many other quantities needed in [7].

$A_{g, c}$ is the (unstressed) canopy gross assimilation rate (net of photorespiration for C3 crops) and is parameterized as in WOFOST crop growth model and adapted to local cultivars [8].

It is emphasized that the inclusion of soil water stress and vapour pressure deficit in the model for canopy resistance is important around Cernavoda area with a dry climate $(500 \mathrm{~mm} / \mathrm{y}$ of rain) and a mix of irrigated and non irrigated cultures. Note also that the canopy resistance depends on the plant phenology (development stage) and our approach includes this considering also local cultivars peculiarity. Soil fertilization increases leaf nitrogen content, as well as the photosynthetic capacity of plant, the canopy resistance and consequently, the exchange velocity.

The above modelling approach must be accompanied by a model of soil water balance in order to have the soil water stress factor. This is done in the frame of assessing the HTO in transpiration flow of crop, because water flow is a driving factor. The optimization of model detail is on going, as we are interested not in robust prediction of HTO dynamic in the soil profile, but on effect on plant HTO concentration through root water for transpiration. Effects of precipitation and irrigation seem important in the acute accidental phase only.

\section{ORGANICALLY BOUND TRITIUM (OBT) FORMATION AND DISTRIBUTION TO EDIBLE PLANT PARTS}

It is now well established that OBT is produced in daylight under photosynthesis, but also in the night under dark reaction. In both cases the HTO concentration in plant water must be known (and it is given by sub-models described above). After the initial formation in leaves, OBT as well as other organic products, is subject of losses through growth and maintenance respiration and is redistributed in various plant parts. Growth and maintenance respiration as well as redistribution are processes in common with carbon. Carbon cycling in vegetation is much more studied and more data are now available (FACE experiments for increased $\mathrm{CO}_{2}$ effect on crops). Most of uncertainties in OBT modelling can be reduced using recent carbon results and dedicated models. It seems now that growth respiration and redistribution are fast processes, while maintenance respiration is a slow one. A time unit of a day is considered for 
modelling these processes, but a shorter one (an hour or less) for the initial production of simple organics containing ${ }^{14} \mathrm{C}$ or OBT, under variable air concentration. Because for daylight production of OBT simple relations can be used linked with carbon, it is desirable to develop first robust operational models for ${ }^{14} \mathrm{C}$, tested with available data. Most plants show that at the beginning of reproductive development stage there is a translocation of organic matter from stems to storage organs. This refers to labile forms of photosynthates stored as reserves. In perennial plants these reserves are the source of spring development. We must distinguish between labile reserve compartment and structural one in storage organs or leaf + stem + root. We decided to develop separate but linked sub-models for perennial or annual crops, with continuous harvest (green stage) or a unique one (drier). An example of model prediction for rice is given in the Figure 1. It uses results from crop growth model for rice and applies for ${ }^{13} \mathrm{C}$ and ${ }^{14} \mathrm{C}$.
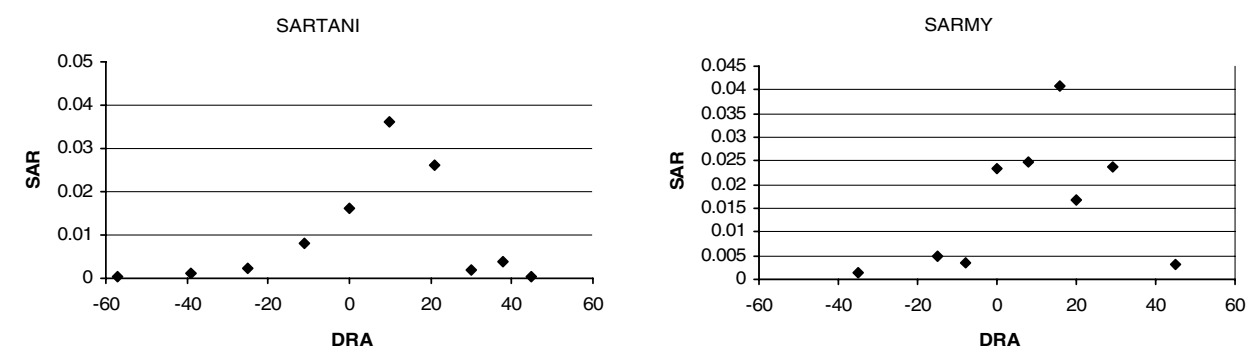

Figure 1. Specific activity ratio SAR after short (7 hours) fumigation of rice at different days after planting (DPA). Left, experimental results, right model results for a close cultivar.

For day light production of OBT, combining the carbon model with the HTO in plant water is enough to deliver reliable model predictions at harvest. Night production of OBT is under debate [3]. Under daylight, starch is mostly produced, but later, different dark reaction ends with a broad range of plant composition. We have sunflower, olives and soybean with high lipid content, but also sugar cane or beet with high carbohydrate content and this must influence dark reaction specificity and consequently, OBT formation in night. At last, for plants having mostly glucose as end product we have an attempt to explain night OBT production [9]. For cereals, night OBT production was initially assessed using general metabolic reaction, but experiments show that we need the minimal reaction rate from the potential range. From present knowledge, night OBT production remains quite uncertain and cannot be ignored.

\section{TRANSFER TO ANIMAL AND HUMAN TRITIUM DOSIMETRY}

There are few experimental data on the transfer of tritium from feed to animal products and recently we advanced a new modelling approach $[10,11]$ based on the working assumption that organic mater turnover rate can be assessed from the turnover rate of net metabolism. Developed as a research tool, the model shows good predictive power and can be used as a background for simpler operational models to be used in practice, as shown recently in an international exercise [12]. Taking the example of transfer in the meat for pork, we can compare the new parameters with those used before in Table 1 . We see that the new model gives a higher transfer factor and a more complex dynamics.

The model was initially developed for mammals and tentatively expanded to birds [10] and needs further experimental confirmation for broiler and egg. Regulatory bodies prefer simple models and we make a trial starting with the simple EDF pig model [12], adding missing pathways and considering in more details growth and metabolism. The growth equation is based on the retained energy, metabolisable energy intake and maintenance metabolism, as well as with relationships between life and empty body 
Table 1. Transfer factors and biokinetic halftime for pig meat (OBT).

\begin{tabular}{|l|c|c|c|}
\hline & unit & FDMH & RECENT \\
\hline TF & d/kg & 0.2 & 0.346 \\
\hline A1 & - & 1 & 0.314 \\
\hline A2 & - & 0 & 0.686 \\
\hline T1/2 1 & d & 10 & 23.6 \\
\hline T1/2 2 & d & Na & 219.7 \\
\hline
\end{tabular}

mass, retained energy and weight gain. Defining the maturity variable $\mu$ as the ratio between actual life mass and mass at full maturity, the growth equation is:

$$
\frac{1}{\mu} \frac{d \mu}{d t}=\lambda_{\text {gain }}-\lambda_{\text {loss }} ; \quad \lambda_{\text {gain }}=L \bullet \lambda_{\text {loss }} ; \quad \lambda_{\text {loss }}=\left(\mathrm{k}_{g}^{*} \mathrm{f}^{*} \mathrm{~g}\right)^{*} \mathrm{a}^{*} \mu^{\mathrm{b}-1} \mathrm{M}^{\mathrm{b}-1}
$$

In above expression we define the level of nutrition, $\mathrm{L}$, as the ratio between metabolisable energy intake and the maintenance energy need, MEm, depending on body mass $B M$ as $M E m=a B M^{b}$. The loss rate depends also on growth efficiency $\mathrm{k}_{\mathrm{g}}$, ratio between empty body gain and retained energy $\mathrm{f}$, and the ratio between life and empty body mass, $g$. Maintenance metabolic rate is used to define the OBT turnover rate. For animals with intensive farming, water intake, $\mathrm{I}_{\mathrm{w}}$, can be linked with body mass as $\mathrm{I}_{\mathrm{w}}=\mathrm{awBM}^{\mathrm{bw}}$. The final model equations for the dynamics of HTO concentration in body water $\left(\mathrm{C}_{\mathrm{HTO}}\right.$ $(\mathrm{Bq} / \mathrm{L}))$ and $\mathrm{OBT}$ in whole body $\left(\mathrm{C}_{\mathrm{OBT}}(\mathrm{Bq} / \mathrm{kg}\right.$ fw $\left.)\right)$ are:

$$
\begin{array}{r}
\mathrm{d} \mathrm{C}_{\mathrm{HTO}} / \mathrm{dt}=\mathrm{c}_{1}\left(\mu^{*} \mathrm{M}\right)^{\mathrm{bw}-1 *} \mathrm{C}_{\mathrm{HTO}, \text { diet }}+\left(\mathrm{c}_{3} \lambda_{\text {loss }} / \mathrm{w}\right)^{*} \mathrm{C}_{\mathrm{OBT}}+(1-\mathrm{frc})^{*}\left(1 . /(w)^{*} \mathrm{c}_{2}^{*} \lambda_{\text {loss }}^{*} \mathrm{C}_{\text {OBTdiet }}\right. \\
\mathrm{C}_{\mathrm{HTO}}\left(\mathrm{c}_{1}\left(\mu^{*} \mathrm{M}\right)^{\mathrm{bw}-1}+k_{\mathrm{hto}}+(\mathrm{L}-1) \lambda_{\text {loss }}\right) \\
\mathrm{d} \mathrm{C}_{\mathrm{OBT}} / \mathrm{dt}=\mathrm{frc}^{*} \mathrm{c}_{2}^{*} \lambda_{\text {loss }}^{*} \mathrm{C}_{\mathrm{OBTdiet}}+\mathrm{k}_{\mathrm{hto}} \mathrm{C}_{\mathrm{HTO}}^{*} \mathrm{~W}-\mathrm{C}_{\mathrm{OBT}}^{*}\left(\mathrm{c}_{3 *} \lambda_{\text {loss }}+(\mathrm{L}-1) \lambda_{\text {loss }}\right)
\end{array}
$$

Model parameters cover water fraction in empty body (w), fraction of intake OBT entering organic compartment (frc), full mature mass (M), transfer rate for metabolisation of OBT from HTO ( $\mathrm{K}_{\mathrm{hto}}$ ) and also c1, c2, c3 depending on body composition, metabolisable energy density in food etc. Parameters values are deduced considering recent farm animal growth models and can be kept at average values in the fattening period of pig, lamb, and broiler. Preliminary tests confirm that the approach is moderately conservative for predicting meat concentration and can be used when tritium experimental data are missing. The simplified model has the advantage of linking animal growth and metabolism parameters with tritium transfer.

For the cow-milk pathways the above simple approach is not possible because milk is mostly a de novo synthesis product. Intensive tests for the model in UFOTRI [13] show remarkable agreement with experimental data if biokinetic rate for OBT is increased about 2 times, close to our metabolic derivation.

The generic model, based on energy metabolism was applied also for humans, for public dosimetry, as an attempt to clarify aspects related to retention, radio-biological effectiveness (RBE), age, gender, race [14]. More recently, we have taken into account the special role of brain in human metabolism and made a careful analysis of all model input, expanding also the model for the case of infants and using recent results on RBE [15]. Comparing to the deterministic ICRP dose coefficients, our results are close (up to $30 \%$ ) for HTO intake, when RBE is ignored. When considering the non-uniform OBT distribution in the body and tissue weighting factors, the dose coefficients are slightly modified. Comparing with our previous results [16], there are minor differences for age older than $1 \mathrm{y}$. When applying an RBE larger than 2, our results are close to previous assessment [17]. HTO dose coefficients are reliable, RBE included.

For OBT intake the situation differs. For the case of $\mathrm{RBE}=1$, our results considering nonuniform distribution of tritium, are again 20-30\% higher than ICRP, but for infant we have a factor 2 
Table 2. Dose coefficients for an OBT intake $\left(\mathrm{Sv} \mathrm{Bq}^{-1} \times 10^{11}\right)$.

\begin{tabular}{|l|c|r|r|r|r|r|r|r|r|r|}
\hline & ICRP & \multicolumn{1}{|c|}{ H (uniform, RBE $=1$ ) } & \multicolumn{1}{|c|}{ H (non-uniform, RBE = 1) } & \multicolumn{3}{|c|}{ E (non-uniform, RBE > 1) } \\
\hline Age & & $5 \%$ & $50 \%$ & $95 \%$ & \multicolumn{1}{c|}{$5 \%$} & $\mathbf{5 0 \%}$ & $95 \%$ & \multicolumn{1}{c|}{$5 \%$} & $\mathbf{5 0 \%}$ & $95 \%$ \\
\hline 3 m & 12 & 26.4 & $\mathbf{2 8 . 9}$ & 31.4 & 20.4 & $\mathbf{2 2 . 5}$ & 24.7 & 65.2 & $\mathbf{7 3 . 5}$ & 81.9 \\
\hline 1Y & 12 & 16.6 & $\mathbf{1 8 . 1}$ & 19.7 & 13.0 & $\mathbf{1 4 . 4}$ & 15.9 & 41.0 & $\mathbf{4 6 . 3}$ & 51.4 \\
\hline 5Y & 7.3 & 9.5 & $\mathbf{1 0 . 5}$ & 11.5 & 8.0 & $\mathbf{8 . 9}$ & 10.0 & 24.7 & $\mathbf{2 7 . 9}$ & 30.9 \\
\hline 10Y & 5.7 & 8.0 & $\mathbf{8 . 7}$ & 9.5 & 5.9 & $\mathbf{6 . 5}$ & 7.3 & 18.2 & $\mathbf{2 0 . 5}$ & 22.8 \\
\hline 15YF & 4.2 & 7.4 & $\mathbf{8 . 1}$ & 8.7 & 5.4 & $\mathbf{6 . 0}$ & 6.7 & 17.1 & $\mathbf{1 9 . 3}$ & 21.4 \\
\hline 15YM & 4.2 & 5.3 & $\mathbf{5 . 9}$ & 6.4 & 4.6 & $\mathbf{5 . 1}$ & 5.7 & 14.4 & $\mathbf{1 6 . 2}$ & 18.0 \\
\hline adF & 4.2 & 8.0 & $\mathbf{8 . 6}$ & 9.2 & 5.2 & $\mathbf{5 . 7}$ & 6.3 & 16.3 & $\mathbf{1 8 . 4}$ & 20.4 \\
\hline adM & 4.2 & 5.3 & $\mathbf{5 . 7}$ & 6.2 & 4.0 & $\mathbf{4 . 5}$ & 5.0 & 12.6 & $\mathbf{1 4 . 2}$ & 15.8 \\
\hline
\end{tabular}

(see Table 2). This can easy be explained. ICRP assumes that the biokinetic rate is given by the balance of carbon intake and carbon body content. Infant uses a large part of the intake for growth and this must be taken into account. For adults our results $(\mathrm{RBE}=1$, uniform) are higher than ICRP by $70 \%$ as an average for man and woman. An increase of dose coefficient for OBT was claimed before only for the specific case of Cardiff bay [18], but our results show that this is general. There are not enough experimental data in order to assess an RBE for OBT case, but it is agreed that it must be higher than for OBT. We use a factor between 1.3 and 2 based on micro-dosimetry estimations. Our results for mean values are higher than ICRP by a factor about 4, due mostly to RBE. They are also higher than previous estimate [17]. Due to uncertainty in the RBE for OBT intake, the dose coefficients are less robust than for HTO case and the infant case merits special attention.

\section{ACCIDENTAL AQUATIC RELEASES OF TRITIUM}

If the terrestrial food chain was analyzed in the past under accidental release of tritium, in many decision support systems (DSS), not too much was done for aquatic accidental releases and we are now in the process of incorporating in the RODOS and MOIRA DSS. The application starts with adaptation of a hydrological model to Danube River and includes an expansion of a previous model [19] for benthic fauna and flora (zoo-benthos, macrophyte), as well as adapted biokinetic parameters for specific Danube fish (small prey fish, carp, pike, catfish, and perch). For an accidental release in Danube of 3.7 PBq, the evolution of water HTO and OBT in aquatic fauna and flora is given in Figure 2. Note the higher peak concentration of zoo-benthos and the long residence of OBT in macrophyte. As for other radionuclide, the residence time in predator fish is longer than for planktivorous ones. River flow and temperature are influencing factors for the variability of public dose and we note a strong seasonality effect (see Figure 2). Including the irrigation pathway, the general conclusion was a 20 fold lower risk than an equivalent atmospheric release.

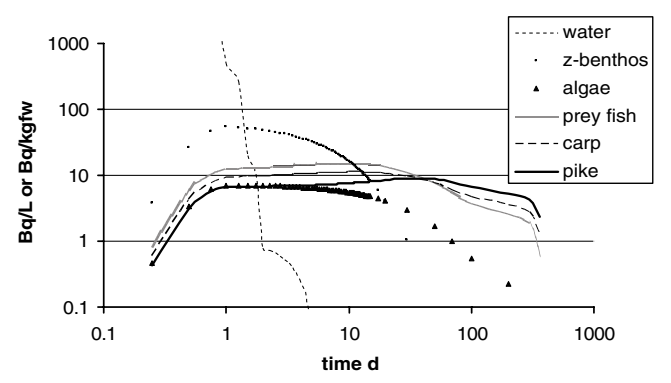

Figure 2. Dynamics of HTO in water and OBT in fauna and flora.
Table 3. Activity intake in humans after ingestion of fish and water.

\begin{tabular}{|c|c|c|c|}
\hline Date & $\begin{array}{c}\text { Ingestion of } \\
\text { T from fish } \\
\text { Bq }\end{array}$ & $\begin{array}{c}\text { Water } \\
\text { OBgestion } \\
\text { Bq }\end{array}$ \\
\hline 15-Feb & 5720 & 3 & 30000 \\
\hline 15-May & 5130 & 15 & 22600 \\
\hline 15-Aug & 19500 & 29 & 68000 \\
\hline 15-Sep & 33550 & 26 & 130000 \\
\hline 15-Oct & 15400 & 17 & 68000 \\
\hline 15-Dec & 11580 & 4 & 56000 \\
\hline
\end{tabular}




\section{CONCLUSIONS}

We discussed some preliminary steps in order to prepare an improved model and code for public risk assessment in the case of accidental tritium releases. We avoided referring on atmospheric transportdispersion itself, as there are today improved models and techniques for input data. We concentrate on some processes where an interdisciplinary approach can offer solutions for more robust modelling hoping that international cooperation will consider the topic in the future. Many results presented in this contribution are preliminary ones from on going work and needs more efforts until use in practice. Due to our assessment of enhanced dose coefficients for infants, a special care must be given to milk pathways. These imply site specific information on local consumption, production area, feeding habits of cow and sheep, distribution network. Effect of accidental release on human milk must also be scrutinized. In the future the assessment must concentrate in reducing uncertainty in terrestrial pathways using site specific data.

\section{Acknowledgments}

We thank to National Agency for Scientific Research, CEEX M3 Contract 81 and CEEX M1 Contract 05-D11-40, as well as NIPNE for their financial support. The authors are grateful to IAEA and IUR for intermediating useful exchanges of idea and results.

\section{References}

[1] P. Guétat, L. Patryl, "Environmental and Radiological Impact of Accidental Tritium Release", Fusion Science and Technology, in press

[2] HPA 2007 "Review of Risks from Tritium", Report of the independent Advisory Group on Ionising Radiation, Health Protection Agency UK, Radiation, Chemical and Environmental Hazards November 2007

[3] D. Galeriu, P. Davis, W. Raskob, A. Melintescu "Tritium radioecology and dosimetry - today and tomorrow", Invited lecture 8th International Conference on Tritium Science and Technology September 16-21, 2007Rochester, New York; accepted in Fusion Science and Technology

[4] Shun'ichi Hisamatsu et all, editors, Procedings of the International Symposium on Environmental Modeling and Radioecology, IES, Japan 2006 ISBN- 978-4-9980604-9-9 C3040

[5] D. Baldochi, 2007 "Lecture on Integrating and Scaling Information from Leaves to Canopy Scales", ESPM 228 and Biometeorology, ESPM 129, University of California, Berkeley

[6] A. Melintescu, D. Galeriu, "A versatile model for tritium transfer from atmosphere to plant and soil", Radioprotection suppl 1 vol 40 pp S437-442 (2005)

[7] R.J. Ronda, H.A.R. De Bruin,and A.A.M. Holstag, J. Appl. Meteorol. 40:1431-1444 (2001)

[8] A. Melintescu, D. Galeriu, E. Marica, "Using WOFOST Crop Model for Data Base Derivation of Tritium and Terrestrial Food Chain Modules in RODOS", Radioprotection, Numero special 37, C1, "The Radioecology - Ecotoxicology of Continental and Estuarine Environments ECORAD 2001", p. 1241-1246 2002

[9] P. Davis, AECL, retired- personal communication

[10] D. Galeriu, A. Melintescu, N.A. Beresford, 2007 "Energy Metabolism - as a General Principle for Modeling the Transfer of Carbon and Tritium across Animals" International Conference on Environment; Survival and Sustainability, 19-24 February 2007, Nicosia, Northern Cyprus

[11] D. Galeriu, A. Melintescu, N.A. Beresford, H. Takeda, N. Crout; "The Dynamic Transfer of ${ }^{3} \mathrm{H}$ and ${ }^{14} \mathrm{C}$ in Mammals-A Proposed generic model" submitted to Radiation and Environmental Byophysics

[12] A. Melintescu, D. Galeriu, 2007 "Tritium transfer in pigs - a model test", accepted in Fusion Science and Technology 
[13] W. Raskob, 1993 "Description of the New Version 4.0 of the Tritium Model UFOTRI Including User Guide", Kernforschungszentrum Karlsruhe GmbH, Karlsruhe

[14] D. Galeriu, A. Melintescu, H. Takeda, 2007, "Risk from tritium exposure", 'IRPA Regional Congress for Central and Eastern Europe' www.irpa2007romania.com sept 24-48, Brasov

[15] M.P. Little and B.E. Lambert 2008 "Systematic review of experimental studies on the relative biological effectiveness of tritium", Radiat. Environ. Biophys. (2008) 47:71-93

[16] A. Melintescu, D. Galeriu, H. Takeda, 2007, "Reassessment of tritium dose coefficients for the general public", Radiation Protection Dosimetry doi10.1093/rpd/ncm267

[17] J.D. Harrison, Khursheed A., Lambert B.E. (2002) "Uncertainties in Dose Coefficients for Intakes of Tritiated Water and Organically Bound Forms of Tritium by Members of the Public", Radiation Protection Dosimetry 98:299-311

[18] A. Hodgson, J.E. Scott, T.P. Fell and J.D. Harrison, 2005 "Doses from the consumption of Cardiff Bay flounder containing organically bound tritium”, J. Radiol. Prot. 25 (2005) 149-159

[19] D. Galeriu, R. Heling and A. Melintescu, "The dynamic of tritium- including OBT- in the aquatic food chain", Fusion Science and Technology, vol 48 no 1 pp 779-782 (2005) 
